\title{
A importância da Matriz SWOT (FOFA) no contexto dos planos estratégicos de desenvolvimento do Rio Grande do Sul
}

\author{
Débora Cristiele Kummer ${ }^{1}$ \\ Rogério Leandro Lima da Silveira ${ }^{2}$
}

\begin{abstract}
RESUMO
O presente artigo tem como suporte a pesquisa Planejamento e Desenvolvimento Regional no Rio Grande do Sul: uma análise da experiência recente dos Conselhos Regionais de Desenvolvimento-COREDEs, concluída em agosto de 2015 pelo Programa de Pós-Graduação em Desenvolvimento Regional (PPGDR-UNISC), no âmbito do Observatório do Desenvolvimento Regional. Teve-se como principal objetivo analisar a construção e implementação dos Planos Estratégicos de Desenvolvimento que foram realizados/atualizados pelos 28 COREDEs nos anos de 2009/2010. A abordagem metodológica é qualitativa em que realizou-se a revisão bibliográfica dos conceitos de planejamento e desenvolvimento regional, bem como a respeito da constituição dos COREDEs no Estado do Rio Grande do Sul. Além disso, fez-se a pesquisa documental dos planos estratégicos e a realização de entrevistas semiestruturadas com lideranças regionais e integrantes das diretorias dos COREDEs. Levando-se em consideração que este trabalho visa dar ênfase a análise da Matriz (SWOT) FOFA dos COREDEs Serra, Sul, Vale do Rio Pardo e Noroeste Colonial apresenta-se como resultados as semelhanças e particularidades que esses apresentam nas Fortalezas (F), Oportunidades (O), Fraquezas (F) e Ameças (A).
\end{abstract}

Palavras-Chave: Planos estratégicos de desenvolvimento. Matriz SWOT. COREDE Serra. COREDE Sul. COREDE Vale do Rio Pardo. COREDE Noroeste Colonial.

\section{ABSTRACT}

This article is supported by the research Planning and Regional Development in Rio Grande do Sul: an analysis of recent experience of the Regional Councils of Development COREDEs, completed in August 2015 by the Postgraduate Program in Regional Development (PPGDR-UNISC) within the Observatory of Regional Development. Had as main objective to analyze the construction and implementation of the Strategic Development Plans that have been performed / updated by 28 COREDEs in the years 2009/2010. The methodological approach is qualitative in which there was the literature review of the concepts of planning and regions development, as well as about the formation of COREDEs in the State of Rio Grande do Sul. In addition, there was a documentary research of strategic plans and carrying out semi-structured interviews with regional leaders and members of the boards of COREDEs. Taking into consideration that this work aims to emphasize the analysis of the matrix (FOFA) SWOT of COREDEs Serra, Sul, Vale do Rio Pardo and Noroeste Colonial present as results the similarities and particularities that those present in the Fortress (F) Opportunities (O), Weaknesses (F) and Threats (A).

Keywords: Strategic Development Plans. SWOT Matrix. COREDE Serra. COREDE Sul. COREDE Vale do Rio Pardo. COREDE Noroeste Colonial.

\footnotetext{
${ }^{1}$ Aluna do Curso de Arquitetura e Urbanismo da Universidade de Santa Cruz do Sul - UNISC.

${ }^{2}$ Professor do Departamento de História e Geografia, e do Programa de Pós-Graduação em Desenvolvimento Regional na Universidade de Santa Cruz do Sul.< rlls@ unisc.br>
} 


\section{INTRODUÇÃO}

Nos anos 90, mais especificamente a partir de 1991, começaram a se constituir no Estado do Rio Grande do Sul os Conselhos Regionais de Desenvolvimento (COREDEs). Isso ocorreu a partir de uma articulação entre o Governo do Estado e instituições regionais, em especial, as universidades e Associação de Municípios. A instituição legal dos COREDEs se deu no ano de 1994 pela Lei Estadual $n^{\circ} 10.283$, e regulamentados através do Decreto ${ }^{\circ}$ 35.764, de 28 de dezembro de 1994.

Os Conselhos têm como principal objetivo tornar o desenvolvimento das regiões mais homogêneo, uma vez que, o Rio Grande do Sul pode ser dividido em três grandes regiões: Região Nordeste a qual tem ênfase na industrialização, sobretudo no eixo Porto Alegre - Caxias do Sul; Região Norte sendo essa uma região heterogênea, onde progressivamente se consolidou o predomínio das lavouras de soja, trigo e milho, e possui ainda algumas cidades que alcançaram um crescimento industrial expressivo. E por fim temse a região Sul que apresenta uma menor participação no PIB do Estado, dentre suas principais características está a concentração de renda, os centros urbanos esparsos e a reduzida densidade da população rural. No entanto, apesar dessas limitações destaca-se pela importância econômica da pecuária extensiva no Estado.

Neste contexto, entende-se a importância dos COREDEs e da elaboração por esses dos Planos Estratégicos de Desenvolvimento os quais nos anos de 2009/2010 foram construídos/atualizados pelos 28 (Vinte e Oito) COREDEs que compõem o Estado do Rio Grande do Sul. Nesse sentido o projeto de pesquisa Planejamento e Desenvolvimento Regional no Rio Grande do Sul: uma análise da experiência recente dos Conselhos Regionais de Desenvolvimento-COREDEs, procurou entender como se realizou esse processo de construção e implementação dos planos. ${ }^{3}$ Devido ao grande número de COREDEs analisados na pesquisa, optou-se por abordar no presente artigo a construção e os resultados da matriz SWOT (FOFA) pelos COREDEs Serra, Sul, Vale do Rio Pardo e Noroeste Colonial, isso devido a essas regiões serem pioneiras no Estado, na elaboração dos planos estratégicos.

Cabe destacar que a matriz SWOT (FOFA), não pode ser considerada a etapa mais importante do processo de construção dos planos estratégicos de desenvolvimento, uma vez

\footnotetext{
${ }^{3}$ Os resultados obtidos nesta pesquisa encontram-se disponível no e-book Observando o Planejamento Regional no Rio Grande do Sul: uma análise da experiência recente dos Conselhos Regionais de Desenvolvimento COREDEs o qual está disponível para download no site da EDUNISC, em: http://www.unisc.br/portal/pt/editora/e-books/408/observando-o-planejamento-regional-no-rio-grande-do-suluma-analise-da-experiencia-recente-dos-conselhos-regionais-de-desenvolvimento-coredes.html.
} 
que, entende-se ser necessário seguir uma sequência para chegar-se até a mesma, porém é por meio da matriz SWOT (FOFA) que é possível entender a região por meio das variáveis internas (Fortalezas e Fraquezas) e das variáveis externas (Oportunidades e Ameaças), sendo que por meio desses dados é possível tanto condicionar/ limitar ou viabilizar/alavancar os projetos e as ações nas regiões. Salienta-se que neste ano (2016) os COREDEs estão atualizando seus planos estratégicos de desenvolvimento, sendo que esta pesquisa de análise a qual foi realizada nos planos de 2009/2010 pode vir a contribuir significativamente para uma melhor elaboração dos novos planos.

Sendo assim, o presente trabalho é composto por cinco tópicos. O primeiro se dá por esta introdução, o segundo baseia-se em revisão bibliográfica com relação aos conceitos de planejamento e desenvolvimento regional, e sobre o processo de constituição dos COREDEs no Rio Grande do Sul. No terceiro discorrer-se-á sobre os procedimentos metodológicos adotados tanto na realização da pesquisa a qual embasa a elaboração desse artigo, bem como o recorte adotado para este artigo. O quarto tópico intitulado Análise da Matriz Fofa dos Planos Regionais de Desenvolvimento apresenta a análise da matriz FOFA dos COREDEs Serra, Sul, Vale do Rio Pardo e Noroeste Colonial. E por fim, o quinto tópico apresenta a conclusão.

\section{FUNDAMENTAÇÃO TEÓRICA}

Segundo Mendes (2008), não há consenso sobre o que seja a definição única de "região". Simplificadamente, a região tem sido considerada um espaço territorialmente delimitado e construído para algum objetivo específico. A região envolve a constituição de espaços com características naturais, sociais, históricos, econômicos, políticos e culturais, comuns. Sua construção envolve necessariamente elementos estruturantes, tais como os recursos humanos, economia, infraestrutura, e fluxos como os de pessoas (migrações), informação, conhecimento, capital, mercadorias e serviços. De modo a promover um desenvolvimento mais homogêneo das regiões tem- se o desenvolvimento regional que para Brandão (2011).

Se por desenvolvimento [regional] entendermos um processo de exercitar opções alternativas frente a uma temporalidade construída e não-imediata, apta a sustentar escolhas, apresentando trajetórias abertas, sujeitas a decisões estratégicas e embates em contexto de incontornável diferenciação de poder (de comando sobre o destino de determinada sociedade), precisamos entender que, ao contrário da preservação de privilégios que representa o processo de crescimento econômico, o desenvolvimento é tensão. É distorcer a correlação de forças, importunar diuturnamente as estruturas e coalizões tradicionais de dominação e reprodução do poder. É exercer em todas as 
arenas políticas e esferas de poder uma pressão tão potente quanto o é a pressão das forças sociais que perenizam o subdesenvolvimento. (BRANDÃO, 2011, p. 34).

Nesse contexto de desenvolvimento regional surgem os Conselhos Regionais de Desenvolvimento - COREDEs os quais devem ser entendidos como Fóruns Regionais de discussão sobre estratégias, políticas e ações que visam o desenvolvimento regional, constituídos como pessoas jurídicas de direito privado, organizados sob forma de associações civis sem fins lucrativos. O desenvolvimento equilibrado e harmônico do Estado a partir do enfrentamento das desigualdades e desequilíbrios econômicos e sociais das regiões sustenta seis objetivos principais relacionados aos COREDEs, em conformidade com sua lei de criação. São eles:
- A promoção do desenvolvimento regional harmônico e sustentável;
- $\quad$ A integração dos recursos e das ações do Governo e da região;
○ A melhoria da qualidade de vida da população;
○ A distribuição equitativa da riqueza produzida;
○ O estimulo a permanência do homem em sua região; e
○ A preservação e recuperação do meio ambiente.

Da mesma forma, as competências dos COREDEs foram estabelecidas na sua lei de criação, com as seguintes atribuições formais:

- Promover a participação de todos os segmentos da sociedade regional no diagnóstico de suas necessidades e potencialidades, para a formulação e implementação das políticas de desenvolvimento integrado da região;

○ Elaborar planos estratégicos de desenvolvimento regional;

- Manter espaços permanente de participação democrática, resgatando a cidadania, através da valorização da ação política;

- Constituir-se em instância de regionalização do orçamento do Estado, conforme estabelece o art. 149. parágrafo $8^{\circ}$. da Constituição do Estado.

- Orientar e acompanhar, de forma sistemática, o desempenho das ações dos Governos Estadual e Federal na região; e

- Respaldar as ações do Governo do Estado na busca de maior participação nas decisões nacionais.

Os Conselhos Regionais de Desenvolvimento seriam então um espaço no qual estariam vinculados Estado e Sociedade que interagiriam por meio da Democracia participativa, ou seja: 


\begin{abstract}
A teoria democrática hegemônica afirma que tal poder deve ser organizado democraticamente através de instituições que intermediam a relação entre os interesses privados dos indivíduos e o próprio poder. A legitimidade do governo residiria na vontade desses indivíduos organizados pelo princípio da maioria, dado que a possibilidade de unanimidade lhe parece ser um ideal contafactual nas sociedades modernas. Decisões legítimas, portanto, são construídas quando baseadas na vontade da maioria e não de todos. Com isso pretende-se não só legitimidade, mas também eficiência no processo de tomada de decisão desses governos. (ELSTER (1986), MAIN (1987), HELD (1995) apud FARIA, 2000, pg. 47).
\end{abstract}

Com a participação da sociedade em prol de seus direitos articulados com o governo pode-se dizer que há o conceito governança territorial o qual no presente artigo o termo restringe-se a escala de análise local/regional e entende-se como:

O exercício do poder e autoridade, por parte dos cidadãos ou grupos devidamente articulados nas suas instituições e organizações regionais, incluindo todos os processos, com o objetivo de diagnosticar a realidade, definir prioridades, planejar a implementação das ações e, assim, determinar como os recursos financeiros, materiais e humanos devam ser alocados, para a dinamização das potencialidades e superação dos desafios, visando ao desenvolvimento de uma região ou território. (DALLABRIDA, 2003; BECKER 2003, p. 80).

Percebe-se então a importância da participação social no que diz respeito ao processo de planejamento e desenvolvimento regional. Principalmente no contexto o qual estamos vivendo, que conforme Rückert (2007):

A crise do nacional-desenvolvimentismo e do planejamento centralizado; as redefinições da geopolítica clássica que perde seus sentidos originais; a tendência às economias flexíveis e à "flexibilização dos lugares", pela alta mobilização do capital e a inserção subordinada dos territórios nacionais periféricos no processo de globalização financeira e de mercados, e a emergência dos processos políticos descentralizantes na face do processo de redemocratização conduzem os Estados do Sul, como um todo e especialmente aos latino-americanos, como o Brasil, a reatualizar suas políticas externas e internas e a requalificar suas opções e necessidades de ordenação territorial e de desenvolvimento. (RÜCKERT, 2007, pg.66).

Dessa forma, o ordenamento territorial tem por função a orientação para um planejamento integrado do espaço, contemplando uma ampla diversidade de elementos, sejam: físicos, humanos ou biológicos, que configuram o território. Sendo conforme Lopes (1997), “(...) como um acto de gestão do planeamento das ocupações, um potenciar da faculdade de aproveitamento das infra-estruturas existentes e o assegurar da prevenção de recursos limitados." Ou seja, é a forma de interação do homem entre o espaço natural ou físico, no entanto, não é apenas à gestão do espaço que importa, também se faz necessário um envolvimento que permita um desenvolvimento em diferentes escalas de modo a preservar o presente e potencializar o futuro. 
Para que o desenvolvimento regional se dê de uma forma adequada, e além da participação social e respeito ao espaço, é preciso buscar o desenvolvimento regional por meio do planejamento em que cabe o conceito de Libâneo (2001) citado por Evangelista (2011, pg. 62), que afirma que "o planejamento é uma prática de elaboração conjunta dos planos e sua discussão pública, é um processo contínuo de conhecimento e análise da realidade [...] em suas condições concretas, busca de alternativas para solução de problemas e de tomada de decisões." Dessa forma, entende-se que o planejamento requer reflexão e ação permanente, sendo esse flexível e sujeito a avaliações constantes, visando retificações em conformidade com seu tempo.

Essa flexibilização do planejamento nos Conselhos Regionais de Desenvolvimento se dá nos planos estratégicos de desenvolvimento em que os 28 COREDEs que compõem o Estado do Rio Grande do Sul, nos anos de 2009 e 2010 elaboraram seus planos quando o Governo do Estado, incentivado pelo Ministério da Integração Nacional, apoiou a realização dos mesmos. Tal iniciativa possibilitou um amplo diagnóstico dos territórios regionais do Estado, estabelecendo uma abrangente agenda de planejamento e de desenvolvimento regional para o território do Rio Grande do Sul.

\section{MATERIAIS E MÉTODOS}

O Projeto de Pesquisa Planejamento e Desenvolvimento Regional no Rio Grande do Sul: uma análise da experiência recente dos Conselhos Regionais de Desenvolvimento COREDEs-RS, o qual se desenvolveu no Observatório do Desenvolvimento RegionalPrograma de Pós-Graduação em Desenvolvimento Regional/UNISC, e contou ainda com parcerias interinstitucionais como a Universidade Federal do Rio Grande do Sul (UFRGS), a Universidade Regional do Noroeste do Estado do Rio Grande do Sul (UNIJUI), a Unidade Integrada do Vale do Taquari (UNIVATES) e a Universidade Federal de Santa Maria (UFSM), possui uma abordagem metodológica qualitativa, a qual envolveu inicialmente a revisão bibliográfica em relação aos conceitos de planejamento e desenvolvimento regional e sobre o processo de constituição dos COREDEs no Rio Grande do Sul, em seguida a pesquisa documental dos planos estratégicos dos COREDES, bem como a realização de entrevistas semiestruturadas com lideranças regionais, membros da sociedade civil e integrantes das diretorias dos mesmos. O projeto em si visa compreender como se deu nos últimos anos o desenvolvimento das políticas públicas de planejamento regional no território do Rio Grande do Sul, isso a partir do processo de construção e implementação dos planos regionais de desenvolvimento. Planos esses, elaborados em 2009 e 2010, por representantes da sociedade 
civil, do Estado e do mercado, coordenados pelos Conselhos Regionais de Desenvolvimento COREDEs em suas regiões de atuação. Os planos foram construídos em cada uma das vinte oito regiões que compõem o Estado, no entanto, devido ao elevado número de regiões e buscando-se uma análise mais aprofundada optou-se, metodologicamente, por trabalhar na pesquisa com quatorze regiões selecionadas, observando ainda pelo menos um COREDE por região funcional do território do Rio Grande do Sul. Diante disso, para a pesquisa selecionouse os COREDEs do Vale do Rio dos Sinos e Vale do Paranhana-Encosta da Serra que compreendem a região funcional 1; Vale do Taquari e Vale do Rio Pardo - Região Funcional 2; Serra-Região Funcional 3; Litoral Norte - Região funcional 4; Sul - Região Funcional 5; Fronteira Oeste - Região Funcional 6; Noroeste Colonial e Celeiro - Região Funcional 7; Jacuí Centro e Central - Região Funcional 8; Alto da Serra do Botucaraí e Produção Região Funcional - 9. Como é possível observar no mapa abaixo (Figura 1):

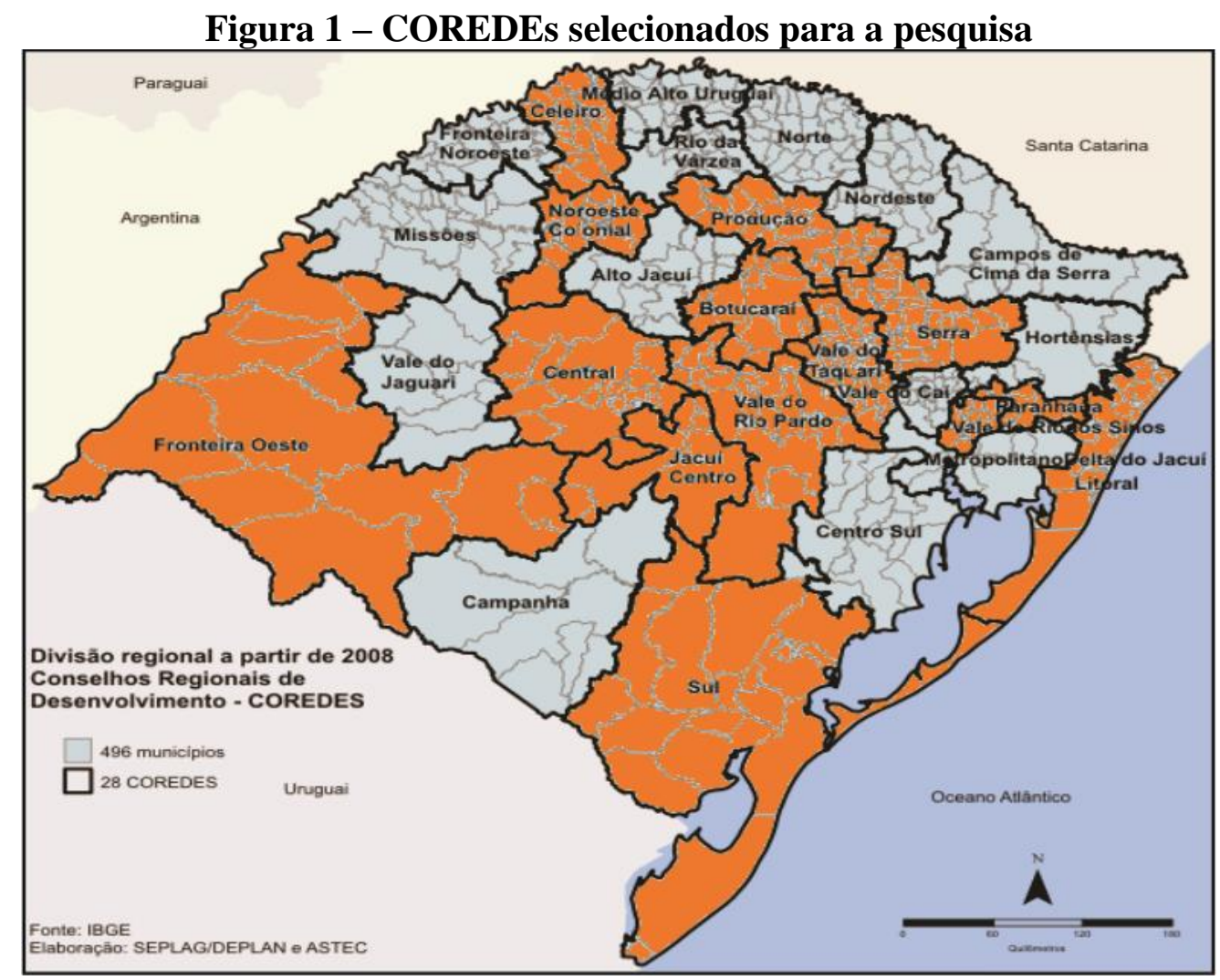

Fonte: SILVEIRA, R. L. L. et al. Observando o Planejamento Regional no Rio Grande do Sul: Uma análise da experiência recente dos Conselhos Regionais de Desenvolvimento - COREDEs. (2015, pg. 13)

Em virtude de ter-se analisado um grande número de COREDEs, para o presente artigo o recorte se dá nos COREDEs Noroeste Colonial, Serra, Sul e Vale do Rio Pardo, isso porque esses tiveram experiências percursoras na realização dos planos estratégicos de desenvolvimento, sendo que dar-se-á ênfase a análise da Matriz (SWOT) FOFA desses 
COREDEs pois, essa é uma das importantes etapas do processo em que as comunidades regionais procuraram pensar e planejar estrategicamente suas regiões. Abaixo segue o mapa destacando os 4 (Quatro) COREDEs analisados (Figura 2).

\section{Figura 2- COREDEs selecionados para análise da Matriz SWOT (FOFA)}

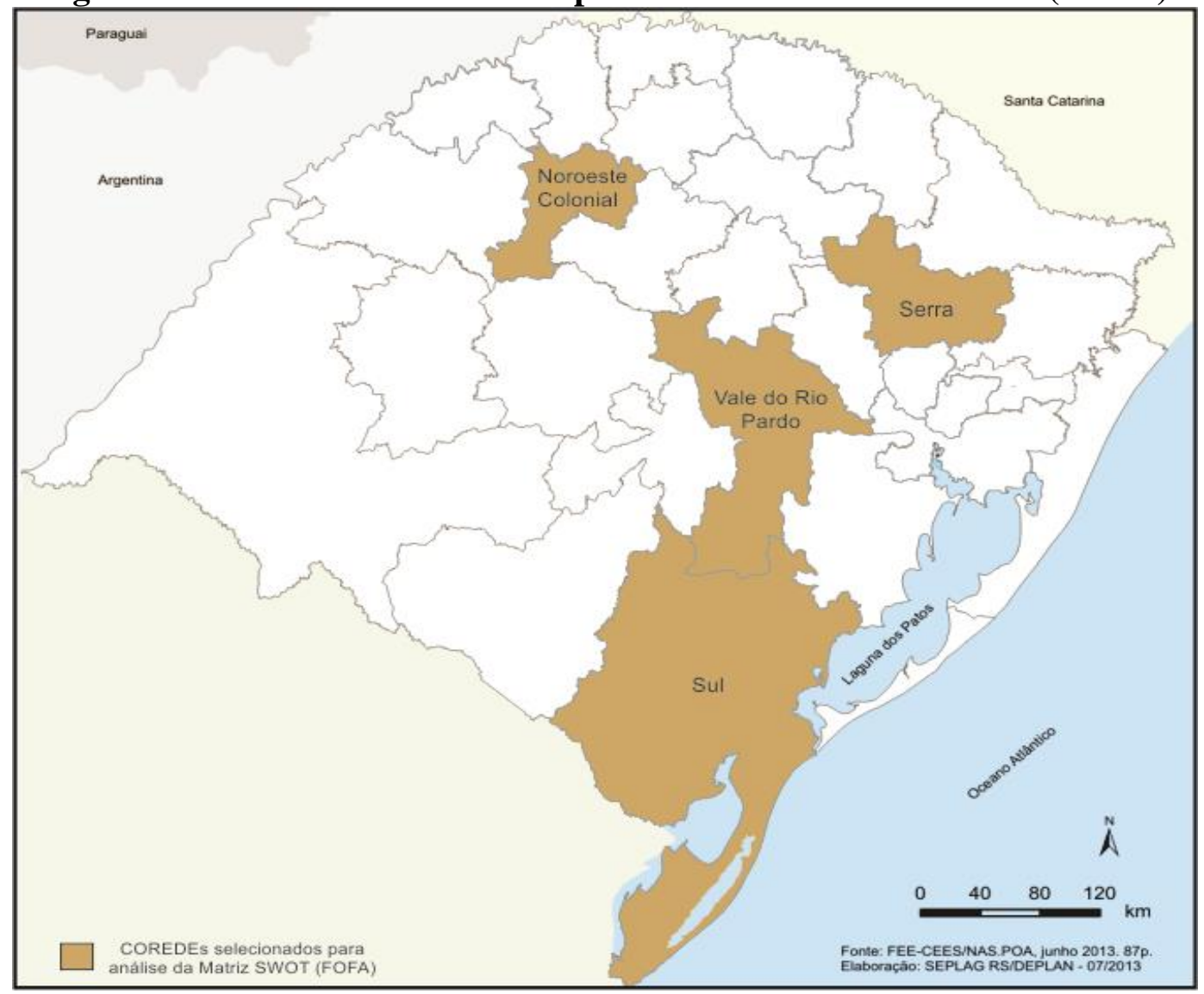

Fonte: SEPLAN-RS/DEPLAN. Perfis por Regiões Funcionais de Planejamento 2015.(2015, Pg.9) Adaptado por Débora C. Kummer, 2016.

\section{ANÁlise dA MATRIZ SWOT (FOFA) DOS PLANOS REgIONAIS DE DESENVOLVIMENTO}

Nos anos de 2009 e 2010, as regiões dos COREDEs no Rio Grande do Sul, embora apresentassem diferentes trajetórias de planejamento regional, buscaram desenvolver e/ou atualizar-se, com apoio dos governos federal e estadual, seus Planos Estratégicos de Desenvolvimento. Sendo assim, ao longo deste ítem discorrer-se-á sobre os Planos Estratégicos de Desenvolvimento que foram elaborados pelos COREDEs nos anos de 2009/2010 com ênfase na matriz SWOT (FOFA) que cada COREDE desenvolveu para sua região de abrangência. De modo que os COREDEs realizassem seus planos estratégicos de desenvolvimento de uma forma coerente e coordenada o Fórum dos COREDEs ofereceu uma 
metodologia a qual foi desenvolvida por Siedenberg et al (2009). Sendo essa, constituída por sete etapas como se observa na Figura 3.

Figura 3 - Síntese das etapas do Planejamento Estratégico

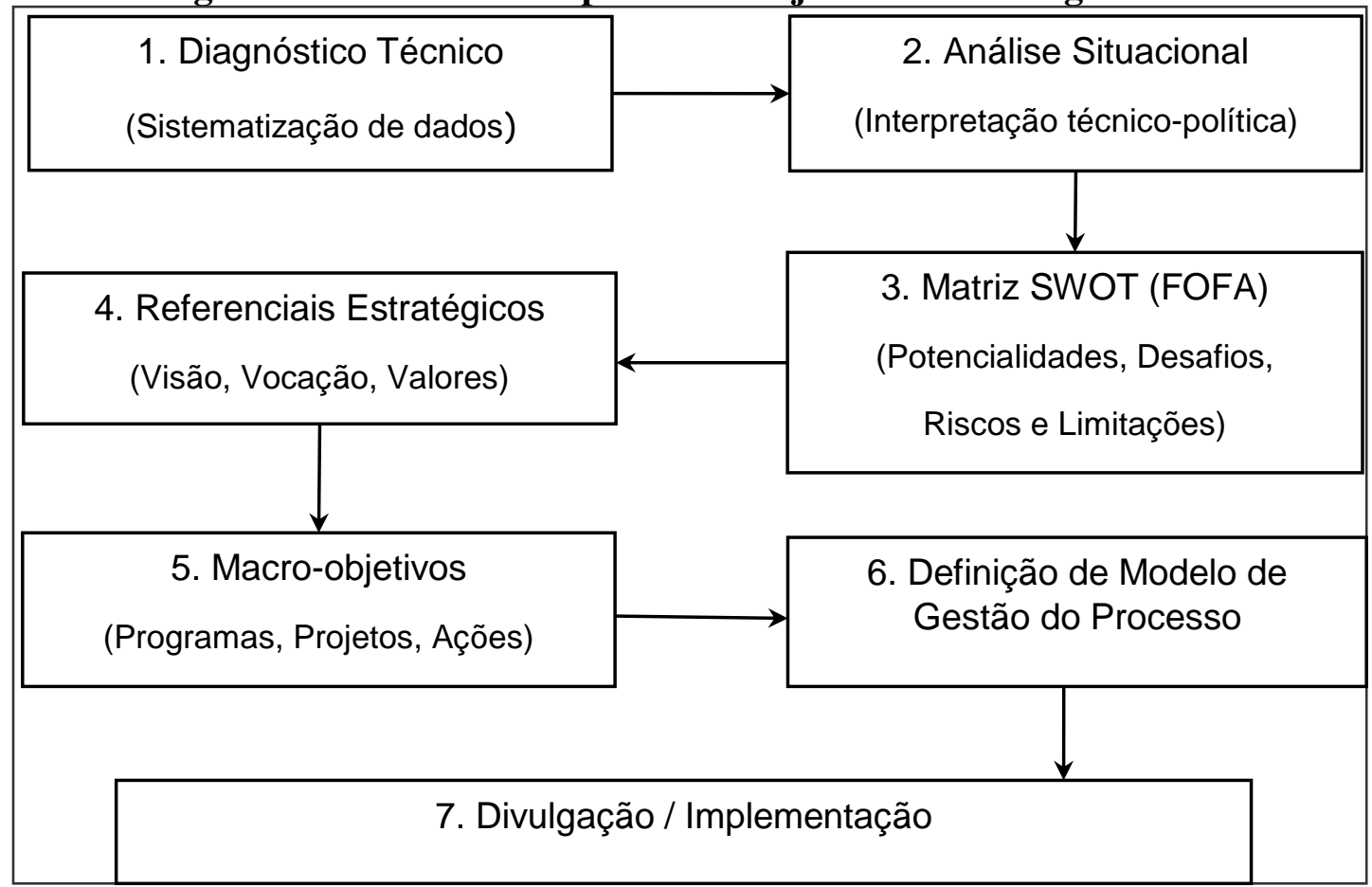

Fonte: SIEDENBERG (Org.) et al (2009, p.30).

Apesar de todas as etapas serem de extrema importância para a execução do plano estratégico de desenvolvimento, destaca-se a Matriz SWOT (FOFA) como um dos momentos crucias do processo uma vez que, é por meio dessa que se conhece as variáveis internas (Fortalezas e Fraquezas) e variáveis externas (Oportunidades e Ameaças) de cada região. A Figura 4 apresenta a configuração do cruzamento dessas variáveis.

Figura 4 - Representação gráfica da matriz FOFA Regional

\begin{tabular}{|c|c|c|c|}
\hline \multirow{2}{*}{\multicolumn{2}{|c|}{ Matriz FOFA }} & \multicolumn{2}{c|}{$\begin{array}{c}\text { Fatores de } \\
\text { Origem interna }\end{array}$} \\
\cline { 3 - 4 } \multicolumn{2}{|c|}{} & $\begin{array}{c}\text { Fortalezas } \\
\vee\end{array}$ & $\begin{array}{c}\text { Fraquezas } \\
\vee\end{array}$ \\
\hline \multirow{2}{*}{$\begin{array}{c}\text { Fatores } \\
\text { de origem } \\
\text { externa }\end{array}$} & Oportunidades $>$ & $\begin{array}{c}\text { Potencialidades } \\
{[++]}\end{array}$ & $\begin{array}{c}\text { Desafios } \\
{[-+]}\end{array}$ \\
\cline { 2 - 4 } & Ameaças $>$ & $\begin{array}{c}\text { Riscos } \\
{[+-]}\end{array}$ & $\begin{array}{c}\text { Limitações } \\
{[--]}\end{array}$ \\
\hline
\end{tabular}

Fonte: SIEDENBERG (Org.) et al (2009, p.30).

Visando facilitar a sistematização dos dados correspondentes a matriz FOFA é proposto a adoção de quatro eixos temáticos os quais se subdividem em demais subgrupos. Esses eixos e subgrupos podem ser observados na Tabela 1. 


\section{Tabela 1 - Síntese de Eixos Temáticos e Subgrupos de Análise}

\begin{tabular}{cc}
\hline $\begin{array}{c}\text { Eixos } \\
\text { Temáticos } \\
\text { Gestão }\end{array}$ & Subgrupos de Análise \\
Estrutural & Saneamento, Energia, Comunicação, Transporte, Meio Ambiente, Habitação e \\
Urbanismo. & Setor Primário, Setor Secundário, Setor Terciário, Mercado de Trabalho, \\
Gestão & Comércio Exterior, Gestão Pública Local. \\
Econômica & Educação, Saúde, Justiça e Segurança, Assistência Social, Cultura, Esporte e \\
Gestão Social & Lazer. \\
Gestão & Articulação e Relações Interinstitucionais, Fomento de Capital Social, Gestão de \\
Institucional & Eventos. \\
\hline
\end{tabular}

Fonte: SIEDENBERG (Org.) et al (2009, p.305).

A partir da matriz FOFA elaborado pelos COREDEs, organizou-se e sistematizou-se os dados os quais foram agrupados em tabelas levando-se em consideração os quatro eixos e as semelhanças/particularidades apresentadas pelos COREDEs Noroeste Colonial, Serra, Sul e Vale do Rio Pardo. No entanto, ressalta-se que o COREDE Serra não apresenta Matriz FOFA em seu plano estratégico, portanto, utilizaram-se as potencialidades como fortalezas e as limitações e problemas como fraquezas, não havendo ameaças e oportunidades. Já nos COREDEs Noroeste Colonial, Sul e Vale do Rio Pardo, que possuem em seus planejamentos estratégicos a Matriz FOFA já cruzada, consideraram-se os desafios como oportunidades, as potencialidades como fortalezas, os riscos como ameaças e as limitações como fraquezas (Tabela 2).

Dentre as semelhanças apresentadas há destaque nas Fortalezas para a presença de associações, instituições e cooperativas nas regiões, a articulação com a população, a presença de feiras e eventos municipais e também as áreas básicas como saúde, educação, cultura, transportes, recursos hídricos e energias. Nas oportunidades identificam-se aspectos como o fortalecimento de programas que visam ao desenvolvimento regional, a valorização do produto primário e as exportações, além da educação, cultura e projetos para o setor de transportes.

As fraquezas presentes nas regiões ocorrem devido há estruturas administrativas deficientes, saúde/hospitais, cultura, sistema de transportes, energia elétrica, recursos hídricos e expansão urbana desorganizada. Quanto às ameaças foram evidenciados aspectos como a violência, as drogas, a criminalidade e a manutenção asfáltica. 
Tabela 2 - Análise comparativa das semelhanças identificadas nos quatro COREDEs ${ }^{4}$

\begin{tabular}{|c|c|c|c|c|}
\hline & Gestão Institucional & Gestão Econômica & Gestão Social & Gestão Estrutural \\
\hline \multirow{16}{*}{$\frac{\sim}{\sim}$} & $\begin{array}{l}\text { Associações/Instituições e } \\
\text { Cooperativas nas regiões }\end{array}$ & Localização Geográfica & Saúde & Transportes \\
\hline & NO/SUL/VRP & NO/VRP & NO/SE/VRP & NO/SUL/VRP \\
\hline & Articulação com a população & Agropecuária & Educação & \begin{tabular}{|c|} 
Distribuição de água/recursos \\
hídricos
\end{tabular} \\
\hline & NO/SUL/VRP & SE/SUL & $\mathrm{NO} / \mathrm{SE} / \mathrm{SUL} / \mathrm{VRP}$ & SE/SUL/VRP \\
\hline & Consórcios & Agronegócio & Cultura & $\begin{array}{c}\text { Diferentes sistemas de } \\
\text { comunicação }\end{array}$ \\
\hline & NO/VRP & SE/SUL & NO/SE/SUL/VRP & $\mathrm{SE} / \mathrm{SUL}$ \\
\hline & Feiras e Eventos Municipais & Polo de Inovação Tecnológica & Diversidade de etnias & $\begin{array}{c}\text { Diversidade biológica e } \\
\text { ambiental }\end{array}$ \\
\hline & NO/SUL/VRP & SE/VRP & NO/VRP & $\mathrm{SE} / \mathrm{SUL}$ \\
\hline & & $\begin{array}{c}\text { Diversificação das culturas } \\
\text { agrícolas }\end{array}$ & População & \\
\hline & & NO/VRP & $\mathrm{SE} / \mathrm{SUL}$ & \\
\hline & & Feiras e Eventos Municipais & $\begin{array}{l}\text { Espírito Empreendedor e } \\
\text { Comunitário na região }\end{array}$ & \\
\hline & & SUL/VRP & $\mathrm{NO} / \mathrm{SE}$ & \\
\hline & & Turismo & & \\
\hline & & SE/SUL/VRP & & \\
\hline & & Disponibilidade e mão de obra & & \\
\hline & & SUL/NRP & & \\
\hline \multirow{18}{*}{ 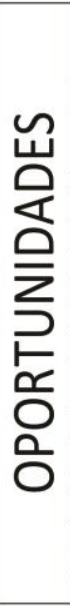 } & \begin{tabular}{|c|} 
Fortalecimento de programas \\
que visam o Desenvovolvimento \\
Regional
\end{tabular} & Incentivos a Pesquisa & Educação & $\begin{array}{l}\text { Projetos para o setor de } \\
\text { transportes }\end{array}$ \\
\hline & \begin{tabular}{|l} 
NO/SUL/VRP \\
\end{tabular} & NO/VRP & NO/SUL/VRP & NO/SUL/VRP \\
\hline & Incentivo a participação popular & Valorização do produto primário & Cultura & Recursos de Infovia \\
\hline & NO/SUL & NO/SUL/VRP & NO/SUL/VRP & SUL/VRP \\
\hline & \begin{tabular}{|l} 
Fortalecer Instituições Regionais \\
\end{tabular} & Exportação & Turismo & Energia \\
\hline & NO/VRP & NO/SUL/VRP & SUL/VRP & SUL/NRP \\
\hline & Fortalecer Politícas Públicas & Rede prestação de serviços & Programas Sociais & Tratamento de Resíduos \\
\hline & $\mathrm{NO} / \mathrm{SUL}$ & NO/VRP & NO/VRP & SUL/VRP \\
\hline & & Capacitações profissionais & & Área Ambiental \\
\hline & & SUL/VRP & & SUL/NRP \\
\hline & & $\begin{array}{c}\text { Incentivo a Implantação de } \\
\text { Agroindústrias }\end{array}$ & & Habitação \\
\hline & & SUL/VRP & & SUL/NRP \\
\hline & & Disponibilidade de Crédito & & \\
\hline & & NO/VRP & & \\
\hline & & Empregos & & \\
\hline & & SUL/VRP & & \\
\hline & & Projetos de Turismo/Hotelaria & & \\
\hline & & SUL/VRP & & \\
\hline \multirow{14}{*}{ 先 } & $\begin{array}{c}\text { Baixa interlocução entre as } \\
\text { instituições }\end{array}$ & $\begin{array}{l}\text { Falta de agregação de valor a } \\
\text { produção }\end{array}$ & Saúde/Hospitais & Ausência de aeroporto regional \\
\hline & $\mathrm{NO} / \mathrm{SUL}$ & $\mathrm{NO} / \mathrm{SE}$ & NO/SE/SUL/VRP & $\mathrm{NO} / \mathrm{SE}$ \\
\hline & Baixa representação política & $\begin{array}{c}\text { Mão de obra } \\
\text { desqualificada/indisponivel }\end{array}$ & Cultura & Sistema de transportes \\
\hline & $\mathrm{NO} / \mathrm{SUL}$ & SE/VRP & NO/SE/SUL/VRP & NO/SE/SUL/VRP \\
\hline & $\begin{array}{c}\text { Estruturas administrtivas } \\
\text { deficientes }\end{array}$ & Exodo Rural & Uso de drogas & Energia elétrica \\
\hline & NO/SUL/VRP & NO/VRP & NO/VRP & SE/SUL/VRP \\
\hline & & Altas taxas de juros & Educação & Recursos hidrícos \\
\hline & & $\mathrm{SE} / \mathrm{SUL}$ & SE/VRP & SE/SUL/VRP \\
\hline & & Justiça e Segurança & & Expansão urbana desorganizada \\
\hline & & SE/SUL & & SE/SUL/VRP \\
\hline & & & & Saneamento \\
\hline & & & & SE/VRP \\
\hline & & & & Urbanismo, plano e gestão \\
\hline & & & & SE/VRP \\
\hline \multirow{10}{*}{$\sum_{\forall}^{\sim}$} & Falta de logística/Infraestrutura & Violência, drogas e criminalidade & Fragilidade no sistema enegético & \multirow{10}{*}{$\begin{array}{l}\text { Não houveram semelhanças na } \\
\text { Gestão Estrutural nas Ameças } \\
\text { entre os COREDEs analisados }\end{array}$} \\
\hline & NO/VRP & NO/SUL/VRP & NO/VRP & \\
\hline & $\begin{array}{l}\text { Dificuldade de acesso aos } \\
\text { recursos }\end{array}$ & Perca da identidade cultural & Sistema de comunicação & \\
\hline & SUL/VRP & NO/VRP & SUL/VRP & \\
\hline & Problemas Ambientais & & Escoamento da safra & \\
\hline & SUL/VRP & & SUL/VRP & \\
\hline & Clima & & Manutenção e acessos asfálticos & \\
\hline & $\mathrm{NO} / \mathrm{SUL}$ & & NO/SUL/VRP & \\
\hline & Serviços púbicos deficientes & & & \\
\hline & NO/VRP & & & \\
\hline
\end{tabular}

Fonte: Os autores.

${ }^{4}$ Os quatro COREDEs analisados são: Serra, Sul, Vale do Rio Pardo e Noroeste Colonial, identificados respectivamente com as siglas SE, SUL, VRP e NO.

Revista Jovens Pesquisadores, Santa Cruz do Sul, v. 6, n. 1, p. 101-115, 2016. 
Já as particularidades as quais estão descritas abaixo, e separadas por COREDE ocorrem devido a aspectos tanto negativos como positivos, considerados como essenciais na caracterização de cada região. No COREDE Sul, por exemplo, devido a seu contingente populacional, há um grande Colégio eleitoral e por apresentar grande extensão territorial há municípios fora do eixo do desenvolvimento regional. Dentre suas características ressalta-se que é uma região litorânea com intenso uso de atividades pesqueiras e a presença do Complexo Porto de Rio Grande. Além disso, nessa região há grande ênfase para as atividades pecuárias, porém, trata-se de uma região com um mercado consumidor distante que apresenta um desenvolvimento desordenado com crescimento populacional exagerado, falta de eventos regionais e problemas turísticos.

No COREDE Serra há uma topografia desfavorável para cultivos temporários, tendo sua estrutura fundiária baseada na pequena propriedade, embora nesta região haja o uso intenso de tecnologia industrial, o que gera um grande índice de empregabilidade. É ainda uma região de atração turística e apresenta a taxa de natalidade como indicativo da qualidade de vida, possui significativa população economicamente ativa. Apresenta êxodo rural sem qualificação da mão de obra, falta de geração de tecnologias de ponta para os sistemas de produção regional e o custo dos imóveis elevados.

No COREDE Noroeste Colonial há destaque para a boa distribuição espacial da população, feiras e exposições, proximidade com o Mercado Comum do Sul (MERCOSUL), boas redes de serviços de saúde e educação. No entanto, é uma região com significativo envelhecimento da população, com a economia dependente do setor primário, sistema de transporte inadequado/frágil, e com deficiências na participação empresarial para o planejamento da região.

Por fim, o COREDE Vale do Rio Pardo apresenta uma produção de culturas diversas na agricultura com clima e solo favoráveis. Constitui-se, ainda, como uma região de acessos intrarregionais possuindo boa localização/logística e corredor de escoamento de produção. Quanto aos aspectos negativos identificam-se a falta de participação da comunidade no planejamento estratégico, um déficit no planejamento turístico e regional, e características de "Bairrismo", o que impedem a identificação de uma perspectiva regional pelos atores envolvidos. Identificaram-se, ainda, problemas de segurança pública, tendo-se como parâmetro o número de policiais com relação à população total, dependência tecnológica externa, êxodo rural e jovens despreparados para o mercado de trabalho. 


\section{CONCLUSÃO}

Diante da análise apresentada das semelhanças e particularidades de cada COREDE, observa-se a importância do plano estratégico de desenvolvimento bem como da Matriz FOFA, pois através destes é possível conhecer a região por meio das variáveis internas (Fortalezas e Fraquezas) e das variáveis externas (Oportunidades e Ameaças) sendo que esses dados apresentam-se como decisivos no planejamento da região, pois podem tanto condicionar/ limitar ou viabilizar/alavancar os projetos e as ações decorrentes.

No entanto, salienta-se que apesar do empenho que os COREDEs realizaram para a execução do plano estratégico, este apresenta-se de modo incompleto e fragmentado como o diagnóstico regional que foi realizado, bem como a maneira superficial como a análise situacional foi realizada, ou até mesmo sua inexistência em quatro Coredes, isso acabou condicionando ou limitando a reflexão e o debate regional, quando da identificação das variáveis internas e externas.

Em alguns planos, a definição dos elementos da matriz FOFA acabou ocorrendo à margem do diagnóstico, já que não havia nenhum registro quanto a dados ou informações que os corroborassem. Isso evidencia que tal definição se deu possivelmente a partir de impressões pessoais, vivências e pontos de vista dos atores regionais presentes nas reuniões realizadas para construir a FOFA regional.

A análise dos planos permitiu também verificar a ausência de uma abordagem que efetivamente contemplasse a totalidade regional, destacando melhor as fortalezas, oportunidades, fraquezas e ameaças regionais, os principais desafios e as demandas prioritárias, que efetivamente tenham uma dimensão e uma importância estratégica para a escala regional. A maior parte dos planos revelou um variado e extenso mosaico de demandas e projetos importantes, mas que ainda se caracterizam pela sua dimensão e abrangência local ou setorial.

Outro aspecto observado na construção da matriz FOFA nas regiões diz respeito à influência ou mesmo um certo condicionamento exercido pela dinâmica de realização do processo de Consulta Popular, através da indicação de demandas prioritárias ao orçamento estadual. Por fim, cabe destacar que atualmente os 28 (Vinte e Oito) COREDEs do Rio Grande do Sul estão atualizando seus Planos Estratégicos de Desenvolvimento com previsão para o término das atividades em dezembro de 2016, nesse sentido entende-se que os resultados da presente pesquisa são de extrema importância para um melhor desenvolvimento das etapas desse processo. 


\section{REFERÊNCIAS}

BRANDÃO, C. A busca da utopia do planejamento regional. Revista Paranaense de Desenvolvimento, Curitiba, n.120, p.17-37, jan./jun.2011. Disponível em: <http://www.ipardes.pr.gov.br/ojs/index.php/revistaparanaense/article/view/263/667〉. Acessado em: 22 Jan. 2016.

DALLABRIDA, V. R.; BECKER, D. F. GOVERNANÇA TERRITORIAL: Um primeiro passo na construção de uma proposta teórico-metodológica. Desenvolvimento em Questão, $\mathrm{n}$. 2, v. 1, p. 73-97, Ijuí: Editora Unijuí, 2003. Disponível em: <https://www.revistas.unijui.edu.br/index.php/desenvolvimentoemquestao/article/view/80>. Acessado em: 24 Jan. 2016.

EVANGELISTA, I. A. S. Planejamento Educacional: Conceções e Fundamentos. Perspectiva Amazônica, v. 02, p. 54-67, Santarém. Pará: Faculdades Integradas dos Tapajós, ago.2011. Disponível em: < http://www.fit.br/revista/doc/2_32.pdf > Acesso em: 21 Fev. 2016.

FARIA, C. F. Democracia Deliberativa: Habermas, Cohen e Bohman. Lua nova - Revista de Cultura e Política, América Latina - São Paulo, n. 49, p. 48 - 68, 2000. Disponível em: < http://www.scielo.br/pdf/ln/n50/a04n50.pdf >. Acessado em: 15 fev. 2016.

FDDR. Planos Estratégicos de Desenvolvimento Regional - Coredes. Fórum Democrático de Desenvolvimento Regional, 2015.2 Disponível em: <http://www2.al.rs.gov.br/forumdemocratico/PlanosEstrat\%C3\%A9gicos/tabid/5363/Default. aspx > Acesso em: 07 ago. 2015.

KIST, R. B. B.; SILVEIRA, R. L. L.; KUMMER, D. C. O Planejamento Estratégico Regional Dos Coredes-Rs: Um Olhar Sobre a Construção da Matriz Swot nos Planos Regionais de Desenvolvimento. VII Seminário Internacional sobre Desenvolvimento Regional, Rio Grande do Sul, $\quad$ Brasil, $2015 . \quad$ Disponível em: <http://online.unisc.br/acadnet/anais/index.php/sidr/article/view/13299>. Acessado em: 15 fev. 2016.

LOPES, H. M. S. Considerações sobre do Ordenamento Território. Revista Millenium, n. 7, Potugal, 1997. Disponível em: 〈http://www.ipv.pt/millenium/ect7_hmsp.htm〉. Acessado em: 21 fev. 2016.

MARINS, K.R.C.C. Política e Planejamento Regional. Texto Técnico da Escola Politécnica da USP, Departamento de Engenharia de Construção Civil, TT/PCC/30. São Paulo: EPUSP, 2012. 26 p. Disponível em: 〈http://www.pcc.usp.br/files/text/publications/TT_00030.pdf> Acessado em: 12 fev. 2016.

MENDES, C.C. O Estado da Política e do Planejamento Regional Recente. In: IPEA. Boletim Regional e Urbano, Brasília, p. 67-72, 2008. Disponível em: <http://ipea.gov.br/agencia/images/stories/PDFs/boletim_regional/081207_boletimregional1_ cap10.pdf > Acessado em: 20 fev. 2016.

RÜCKERT, A. A. A Política Nacional de Ordenamento Territorial, Brasil. Uma política territorial contemporânea em construção. Revista electrónica de geografía y ciencias sociales, Vol. XI, n. 245 (66), Barcelona, 01 ago.2007. Disponível em: < http://www.ub.edu/geocrit/sn/sn-24566.htm> Acessado em: 12 fev. 2016. 
SEPLAN-RS/DEPLAN. Perfis por Regiões Funcionais de Planejamento 2015. Porto Alegre, 2015. Disponível em:<http://www.seplan.rs.gov.br/conteudo/3635/Perfis-por-RegioesFuncionais-de-Planejamento> Acesso em: 22 Fev. 2016.

SIEDENBERG, D.; (Org.) ALLEBRANDT, S. L.; BÜTTENBENDER, P. L. e FRIZZO, P. A. Orientações para o Processo de Planejamento Estratégico Regional dos COREDES-RS. Ijuí: Editora Unijuí, 2009.

SILVEIRA, R. L. L. et al. Observando o Planejamento Regional no Rio Grande do Sul: Uma análise da experiência recente dos Conselhos Regionais de Desenvolvimento - COREDEs. Santa Cruz do Sul: EDUNISC, 2015. Disponível em: $<$ http://www.unisc.br/portal/pt/editora/e-books/408/observando-o-planejamento-regionalnorio-grande-do-sul-uma-analise-da-experiencia-recente-dos-conselhos-regionais dedesenvolvimento-coredes.html. > Acesso em: 27 Jan. 2016.

\section{Como citar este documento:}

KUMMER, Débora Cristiele; SILVEIRA, Rogério Leandro Lima da. A importância da Matriz SWOT (FOFA) no contexto dos planos estratégicos de desenvolvimento do Rio Grande do Sul. Revista Jovens Pesquisadores, Santa Cruz do Sul, v. 6, n. 1, jun. 2016. ISSN 2237-048X. Disponível em: $\langle$ https://online.unisc.br/seer/index.php/jovenspesquisadores/article/view/7250>. Acesso em: doi:http://dx.doi.org/10.17058/rjp.v6i1.7250. 